\title{
Chronic obstructive pulmonary disease (COPD) and lung cancer: common pathways for pathogenesis
}

\author{
Brielle A. Parris ${ }^{1}$, Hannah E. O'Farrell ${ }^{1}$, Kwun M. Fong ${ }^{1,2}$, Ian A. Yang ${ }^{1,2}$ \\ ${ }^{1}$ UQ Thoracic Research Centre, The Prince Charles Hospital, University of Queensland, Brisbane, Australia; ${ }^{2}$ Department of Thoracic Medicine, \\ The Prince Charles Hospital, Metro North Hospital and Health Service, Brisbane, Australia \\ Contributions: (I) Conception and design: All authors; (II) Administrative support: None; (III) Provision of study materials or patients: None; (IV) \\ Collection and assembly of data: None; (V) Data analysis and interpretation: None; (VI) Manuscript writing: All authors; (VII) Final approval of \\ manuscript: All authors. \\ Correspondence to: Hannah E. O'Farrell. UQ Thoracic Research Centre, The Prince Charles Hospital, Rode Road, Chermside 4032, Queensland, \\ Australia. Email: hannah.ofarrell@uq.net.au.
}

\begin{abstract}
Chronic obstructive pulmonary disease (COPD) and lung cancer comprise the leading causes of lung disease-related mortality worldwide. Exposure to tobacco smoke is a mutual aetiology underlying the two diseases, accounting for almost $90 \%$ of cases. There is accumulating evidence supporting the role of immune dysfunction, the lung microbiome, extracellular vesicles and underlying genetic susceptibility in the development of COPD and lung cancer. Further, epigenetic factors, involving DNA methylation and microRNA expression, have been implicated in both diseases. Chronic inflammation is a key feature of COPD and could be a potential driver of lung cancer development. Using next generation technologies, further studies investigating the genomics, epigenetics and gene-environment interaction in key molecular pathways will continue to elucidate the pathogenic mechanisms underlying the development of COPD and lung cancer, and contribute to the development of novel diagnostic and prognostic tools for early intervention and personalised therapeutic strategies.
\end{abstract}

Keywords: Pulmonary disease; chronic obstructive; lung neoplasms

Submitted Sep 04, 2019. Accepted for publication Oct 18, 2019.

doi: $10.21037 /$ jtd.2019.10.54

View this article at: http://dx.doi.org/10.21037/jtd.2019.10.54

\section{Introduction}

Chronic obstructive pulmonary disease (COPD) is a preventable and treatable condition characterised by persistent respiratory symptoms and enhanced inflammatory response due to noxious particles and gases (1). While COPD is often associated with other chronic conditions including emphysema and bronchitis, a substantial number of patients suffer from exacerbations which often require hospitalisation. Increased frequency of severe exacerbations of COPD is linked to significantly worsened survival outcomes (2).

COPD is a major public health concern affecting approximately 251 million people globally $(1,3)$. In Australia, a reported $\$ 929$ million per annum is spent on direct health expenditure attributed to COPD, significantly burdening the health care system (4). COPD currently affects $8-10 \%$ of adult populations in the developed world and $15-20 \%$ of smokers. The World Health Organisation has projected that COPD will become the $3^{\text {rd }}$ leading cause of death globally by 2030 unless vital action is taken to reduce underlying risk factors, principally tobacco smoking and passive exposure to environmental pollutants (5).

Lung cancer is the leading cause of cancer-related mortality, accounting for almost a fifth of all cancer deaths worldwide (6). By 2030, it is estimated that the number of lung cancer deaths will rise to 10 million per year (7). Despite advancements in survival outcomes for patients with other cancer types, the current overall 5 -year survival rate of patients with lung cancer of $16 \%$ has remained 
relatively unchanged in the past three decades (8).

Lung cancer is a genetically complex and heterogeneous disease, caused by mutations in oncogenes resulting in the progressive transformation of normal cells to malignant derivatives under the influence of genetic and epigenetic alterations (9). This is further perpetuated by the evasion of normal regulatory systems in the immune system and defective mechanisms that govern normal cellular activity and homeostasis (10). Lung cancer comprises two major subtypes-non-small cell lung cancer (NSCLC) and small cell lung cancer (SCLC); which are differentiated by their cellular origin and phenotype. NSCLC comprises the majority (85\%) of cases and arises from epithelial cells of the lung. NSCLC is further divided into adenocarcinoma, squamous cell carcinoma and large cell carcinoma. SCLC has distinct histological features of neuroendocrine differentiation and small cells with scant cytoplasm and accounts for approximately $15 \%$ of cases (11).

This review will discuss common pathogenic pathways contributing to the COPD and lung cancer, and how certain molecular and cellular mechanisms differ. Further understanding of the shared molecular pathways between these two lung diseases will highlight the direction of future studies required for the development of earlier diagnosis and therapeutic strategies.

\section{Epidemiological evidence linking COPD and lung cancer}

\section{Tobacco smoking}

Exposure to tobacco smoke is the leading cause of preventable disease and the most common risk factor for COPD and lung cancer, accounting for almost $90 \%$ of cases. People with COPD carry a greater risk of lung cancer (12) which suggests that shared pathological mechanisms such as chronic inflammation, epigenetic changes, and impaired DNA repair processes as a result of oxidative stress (13). Oxidative stress from exogenous and endogenous factors, autoantibody expression, protease activity and the release of pro-inflammatory cytokines are all known to cause airway destruction, lung hyperinflation and air trapping, damaging the lungs in people with COPD (Figure 1) (14). This repetitive lung injury eventually causes airflow limitation, further contributing to impaired clearance of inhaled toxic particles and increasing exposure at the epithelial level. As a consequence, the chronic inflammation, immune cell infiltration and oxidative stress persists long after inhalation has ceased $(15,16)$.

Among smokers, COPD is an important risk factor for developing lung cancer, and predates lung cancer in up to $70-80 \%$ of cases (17). A seminal cohort study by Mannino et al. revealed a distinct linear dose-response relationship between increasing COPD severity and risk of lung cancer (18). A large retrospective study of patients with lung cancer showed that the coexistence of COPD predicted a significantly worse survival outcome $(12,19,20)$. The presence of emphysema has been shown to confer a significant risk of developing lung cancer, particularly squamous cell carcinoma and SCLC (20). Overall, people with COPD have an increased risk (4- to 6-fold) of developing lung cancer, independent of smoking history, age and sex $(12,19)$.

\section{Occupational and environmental air pollution}

Industrial exposure to various metals, dusts and fumes are under-appreciated risk factors for COPD $(21,22)$. Comparatively, the causal link between occupational exposures such as asbestos fibres (23) and radon $(24,25)$ as a primary cause of lung cancer is well established. Exposure to particulate matter in urban air has been shown to present a $14 \%$ increase in risk of lung cancer with every $10 \mathrm{~g} / \mathrm{m}^{3}$ increase in concentration of fine particles (26). A recent cross-sectional analysis by Liu et al. revealed a strong association between COPD prevalence and urban particulate matter (27).

Among low-income countries, indoor air pollution is the leading risk factor for COPD and lung cancer (28). Indoor air pollution from combustion of biomass fuels such as wood and coal increase disease risk due to the increase in toxic particulate matter, polycyclic aromatic hydrocarbons (PAHs) and heterocyclic aromatic compounds (29). This presents a significant public health problem as these fuel sources are used by over 3 billion people for cooking and heating (30).

Asian women have a disproportionately high incidence of lung cancer compared with women of other ethnicities, despite cigarette smoking being uncommon in this demographic (31). Several epidemiological studies have reported cooking oil vapours and inadequate kitchen ventilation as a risk factor for both lung cancer $(7,32,33)$ and COPD (34-36). Further studies of women in China (37) and Taiwan $(38,39)$ have reported a dose-response relationship for lung cancer risk and use of volatilised oils, citing the mutagenic or oxidative effects of various components found 


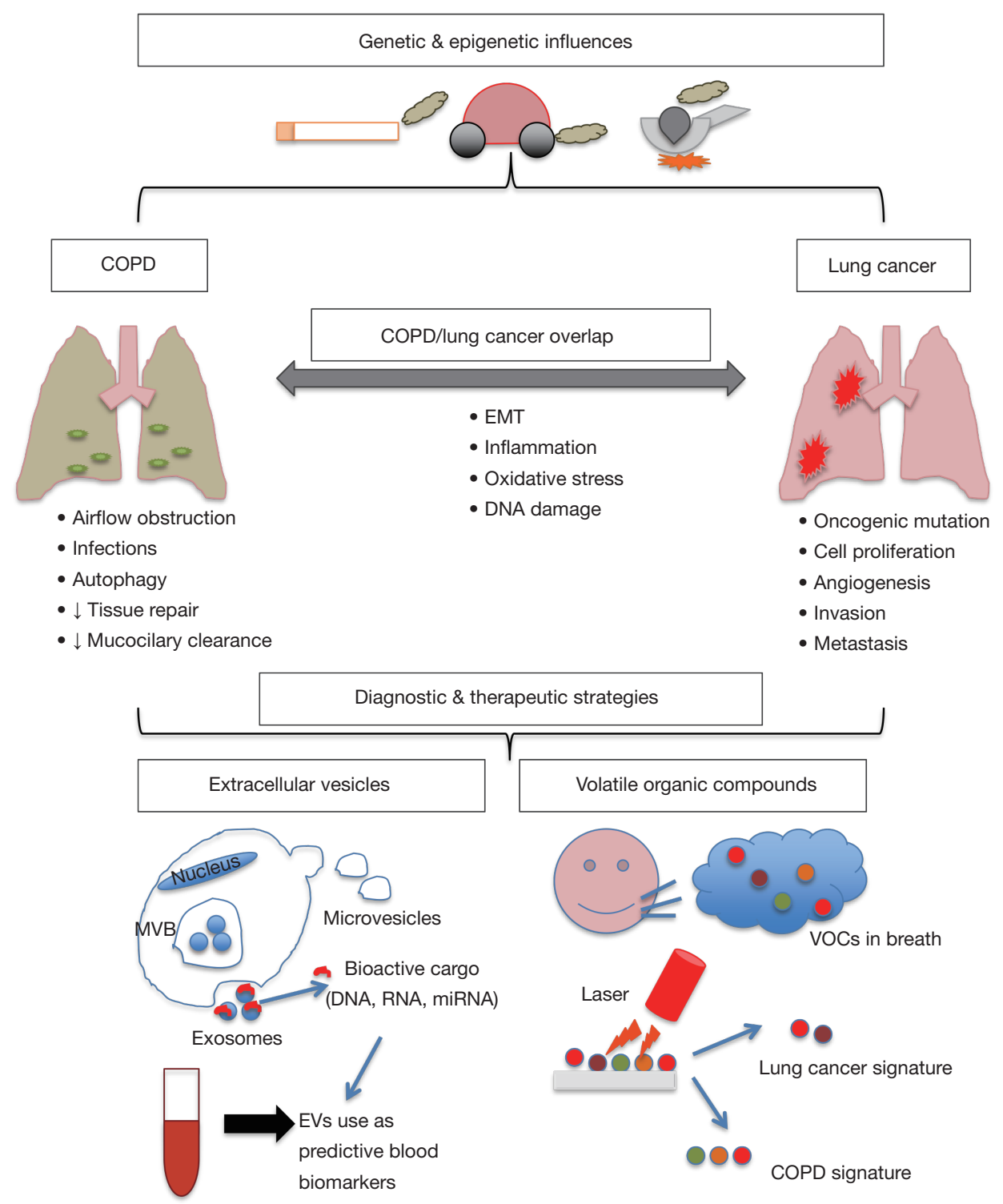

Figure 1 Genetic \& epigenetic influences that can lead to COPD and lung cancer development. COPD and lung cancer, while distinct diseases, share similar pathogenic mechanisms, including EMT, inflammation, oxidative stress and DNA damage. Novel diagnostic and therapeutic strategies currently under investigation include: extracellular vesicles, which are formed inside MVB, which then fuse the plasma membrane to release bioactive cargo into the extracellular space; volatile organic compounds, which can be detected in patients breath, also holds diagnostic potential for lung diseases through the identification of unique signatures. COPD, chronic obstructive pulmonary disease; EMT, epithelial-mesenchymal transition; MVB, multivesicular bodies; VOCs, volatile organic compounds; EVs, extracellular vesicles.

in aerosolised oils $(40,41)$.

\section{Genetic and epigenetic mechanisms linking COPD and lung cancer}

Phenotypically, COPD and lung cancer present as very dissimilar diseases. COPD has features of chronic lung damage, characterised by irreversible airflow limitation, inflammation of small airways and progressive destruction of distal lung parenchyma resulting in emphysema (42). In comparison, lung cancer is characterised by DNA damage resulting in the overproduction of stimulatory 
proteins, excessive unregulated proliferation and defective cell cycle checkpoint regulation which confers selective biological advantage over normal cells (43). While tobacco smoking is the main risk factor for lung cancer and COPD development, only $10-20 \%$ of smokers develop COPD (44) and $10-15 \%$ of individuals develop lung cancer despite being never-smokers (45). While not all smokers will develop lung cancer, the environmental exposure to tobacco smoke and volatile agents unmask the fundamental genetic differences and the varying degrees of susceptibility to these lung diseases among smokers.

\section{COPD}

Early genetic studies of familial linkage in COPD identified that mutations in the SERPINA1 gene resulted in severe alpha1-antitrypsin (AAT) deficiency and accounted for $\sim 1 \%$ of cases (46). More recently, genomewide association studies (GWAS) have been performed to identify associations between chromosomal regions and disease phenotypes in order to predict disease risk or susceptibility. A large GWAS and meta-analysis by Cho et al. confirmed three known loci at CHRNA3, CHRNA5, $F A M 13 A$, and HHIP loci were associated with increased risk of COPD, as well as MMP12, TGFB2 and the novel RIN3 locus (47).

\section{Lung cancer}

Large scale genomic profiling studies have revealed the molecular complexity of lung cancer $(48,49)$. On the spectrum of mutational frequencies among cancer types, compared to paediatric cancers $(0.1 / \mathrm{Mb})$, the high mutation frequency in lung cancer $(100 / \mathrm{Mb})$ is mostly attributable to extensive carcinogenic exposure to tobacco smoke and other known inhaled carcinogens (50). Despite the wellestablished causality between tobacco smoke and lung cancer, there is accumulating evidence to suggest there is also a hereditary component to lung cancer susceptibility (51). The heritability of lung cancer is estimated to be between $15-25 \%$ (52), with risk increasing by approximately $50 \%$ for patients who have first degree relatives (52), particularly when the relative was diagnosed at a young age and cases where multiple family members are affected $(53,54)$. Early linkage analyses of 52 lung cancer affected families identified a high penetrance susceptibility locus in the 6q23-25 region (52). Further analyses on 93 high-risk families confirmed this rare genetic variant significantly increases lung cancer risk and ongoing targeted sequencing studies seek to identify a causal variant (55).

Lifelong never-smokers account for $25 \%$ of lung cancer cases and harbour specific molecular and pathological features (56). More than half of women with lung cancer have never smoked; however these figures vary between certain geographical locations (Asia > North America > Europe) (57). Studies have suggested that a hormonal element, hereditary risk and certain environmental exposure may influence this unique subset of patients (56). Polymorphisms in CYP1A1 and GTSM1, xenobiotic metabolising enzymes, are associated with lung cancer risk in Caucasian non-smokers (58), and polymorphisms in MLH1, a mismatch pair enzyme, have been cited to have a role in the development of cancer in the absence of tobacco smoke (59). In never smokers, polymorphisms in genes associated with inflammatory pathways, including interleukin (IL)-10, tumour necrosis factor (TNF) (60), IL1-RN and IL-6 (61), are associated with an increased risk of lung cancer.

\section{Lung cancer and COPD genetic overlap}

The COPD and lung cancer overlap may exist beyond their smoking-induced pathogenic processes through shared genetic susceptibility (62). GWAS investigating lung function and lung cancer have identified associations with several overlapping loci, supporting the notion that some of the loci that determine COPD susceptibility are also important for lung cancer susceptibility in smokers (63-65). Epithelial-mesenchymal transition (EMT) is a pathogenic feature of COPD and lung cancer as well as inflammation, and the rs7326277TT genotype in VEGFR1 promotes these processes as well as tumour growth and is a susceptible locus in both diseases (Figure 1) (66). Additionally, an increased risk of COPD and lung cancer has also been demonstrated in polymorphisms in the anti-inflammatory gene $\operatorname{IL10}(67,68)$.

An early GWAS using sub-phenotyped smoker control groups identified overlapping loci at chromosome $15 \mathrm{q} 25$ and $4 \mathrm{q} 31$ in both COPD and lung cancer $(69,70)$. Chromosome $15 \mathrm{q} 25$ locus has been shown to be independently associated with COPD susceptibility $(16,36,58,69)$, while chromosome $4 \mathrm{q} 31$ locus associated with a reduced risk of COPD, as well as lung cancer independent of COPD $(64,70,71)$. More recently, a large GWAS of over 250,000 individuals identified 35 new genetic risk loci for COPD, of which 13 of these 35 were associated with lung function, supporting the genetic susceptibility component of COPD development. Bioinformatics analysis of this 
data further elucidated the biological pathways, genes and cells were implicated and potential therapeutic targets (72). However it has been suggested that some GWAS studies may have underestimated the contribution of COPD and its underlying genetic determinants of lung cancer, since spirometry is not routinely performed for lung cancer studies (73). Further, a comprehensive understanding of how these genes are implicated in the molecular pathogenesis of COPD and lung cancer will require further studies integrating next-generation technologies and omics data.

\section{Somatic mutations}

Somatically acquired loss-of-function mutations in PTEN and TP53 and gain-of-function mutations in EGFR and Ras are frequently persistent in epithelium of smokers and patients with lung cancer (74). EGFR and KRAS are two of the most commonly mutated oncogenes in adenocarcinoma, with EGFR being found to be over-expressed in 40-80\% of NSCLC cases and associated with higher metastatic and tumour proliferation rate, advanced staging and poorer prognosis $(75,76)$. Further mutant forms of $E G F R$ (deletion in exon 19 and L858R in exon 21) with tyrosine kinase activity have been identified to play a role in lung carcinogenesis and further have been considered targets for treatment $(77,78)$. This led to the development of specific EGFR tyrosine kinase inhibitors, such as gefitinib and erlotinib which were approved by the FDA as therapeutics for advanced and metastatic NSCLC $(79,80)$. These drugs act by inhibiting receptor phosphorylation in the intracellular domain by competing with ATP for the for the ATP binding site (80). It has been proposed that the incidence of EGFR mutations is due to genetic instability causing gene amplification (81).

Due to the proven mutagenic effect of cigarette smoke, it is thought that acquired somatic mutations, rather than germline polymorphisms may contribute to the molecular pathogenesis of COPD (82). Early evidence suggests that there is a link between somatic mutations and COPD pathogenesis, however this mutated gene clustering has not been shown to definitely contribute to COPD. Nuclear factor kappa B (NF- $\mathrm{B}$ ) and activator protein 1 (AP-1) signalling is upregulated in epithelium of smokers and COPD patients. Consequently, amplification of NF- $\mathrm{BB}$ and AP-1 signalling is mediates the expression of inflammatory cytokines and proteinases in response to oxidative stress (83). Further, the presence of these somatic mutations and their intermediate molecules converge with transcription factors causing an altered bronchial epithelium phenotype in the form of squamous metaplasia (84). This impaired phenotype contributes to COPD through compromised immune defence contributing to persistent inflammation, recurrent infections and insensitivity to inhaled corticosteroids in some patients (82).

\section{Epigenetics}

Distinct from somatic mutations and underlying genetic predisposition, epigenetic alterations are modifications that influence gene expression without changes to the nucleotide sequence. Tobacco smoking-induced modification to the airways and lungs of patients with lung cancer and COPD has been shown to influence epigenetic alterations including DNA methylation, microRNA expression and histone acetylation (85).

\section{DNA metbylation}

DNA methylation is the reversible modification of DNA structure by the addition of a methyl group to the $5^{\prime}$ position of a cytosine residue (86). This process can be a part of a $\mathrm{CpG}$ island or cluster of tumour suppressor genes, which increase proliferation (87). In relation to COPD, DNA methylation is most likely attributed to hypomethylation of immune-modulatory genes such as SERPINA1 encoding alpha1-antitrypsin, leading to gene overexpression (88).

In lung cancer, both promoter and tumour suppressor genes are observed to be hypermethylated. The reversibility of methylation makes it an attractive target for cancer therapy (89). DNA methylation profiles may be able to distinguish between smokers and COPD, as well as different subtypes of NSCLC (85) and therefore characterising methylation signatures in peripheral blood may have a potentially important role as a biomarker for diagnosis and disease monitoring (88).

In an epigenome wide association study, DNA methylation and the repression of genes $C C D C 37$ and $M A P 1 B$ were identified to be significantly more prevalent in patients with both lung cancer and COPD, compared to non-COPD cases. Lung cancer patients showed a higher degree of methylation than COPD patients (90).

\section{MicroRNA (miRNA) regulation}

miRNAs are small non-coding RNA molecules and primary 
epigenetic mediators involved in critical posttranscriptional regulation, through either translational repression or degradation of target mRNA (91). More than $60 \%$ of protein-coding genes are subjected to regulation by miRNAs (92). Owing to their broad range of target genes, they are involved in regulating many key physiological processes such as cell metabolism, apoptosis, tissue differentiation and DNA repair (91), as well as the initiation and progression of pathogenic processes leading to chronic infection, inflammation (93) and tumorigenesis (44).

A recent study highlighted the significant downregulation of miR-218-5p in the lung tissue of COPD patients compared with never smokers, and was strongly correlated with severity of airway obstruction (94). Clinical and preclinical validation further showed that the highest expression of miR-218-5p was localised at the bronchial airway epithelium. Further perturbation experiments suggest that miR-218-5p may have a role in defence against cigarette smoke-induced inflammation and COPD pathogenesis (94).

Disease-specific miRNA expression patterns are promising diagnostic and prognostic biomarkers in NSCLC and COPD (95). Recently, Keller et al. profiled miRNAs in the blood of COPD patients and identified nine miRNAs significantly downregulated in patients who developed lung cancer. Candidate miRNAs were implicated in the regulation of cancer-related pathways including MAP kinase, integrin signalling and focal adhesion (96). Further, using a three-miRNA classifier (miR-450a-5p, miR-4677-3p, and miR-9-3p), an area under the curve (AUC) of 0.87 predicted the development of lung cancer ( $v s$. no cancer) among the COPD patients.

Recently, Mateu-Jimenez and colleagues revealed that the expression of a four-miRNA signature (miR-21, miR-200b, miR-210, miR-let7c) and total DNA methylation was increased in lung cancer patients with COPD compared to those without (97). Further, the tumours of the COPD-lung cancer patients harboured decreased expression of the miRNA target genes including PTEN, MARCKs, and KRAS compared to patients without COPD. This study highlighted the significant role of epigenetics in regulating cellular pathways that increase risk of tumorigenesis in COPD and how epigenetics profiles may influence the efficacy of cancer treatments among patients with underlying respiratory disease (97).

\section{Gene expression in COPD and lung cancer}

Large gene expression profiling studies have been performed to better understand the pathogenesis of COPD and lung cancer through quantification of the transcriptome $(72,98)$. The advancements in omics technologies has seen a shift towards analysis and publication of multi-omics datasets, whereby the use of transcriptome, translatome and proteome data is used to enhance the accuracy and validity of molecular studies (99). The lung stroma is a composition of fibroblasts and mesenchymal stromal cells that form a structural and functional support network for tissues (100). Recently, a multi-omics approach was used by Sandri and colleagues to characterise two distinct stromal gene expression patterns in lung cancer that diverged on the basis of lung function $\left(\mathrm{FEV}_{1}\right)(101)$. Patients with normal to mild impairment demonstrated mammalian target of rapamycin (mTOR)-predominant pathway activation to drive cancer development. Conversely, the stroma of patients with severe airflow obstruction coordinated cancer-associated signalling via the fibrotic extracellular matrix (ECM). It has been suggested that further investigation into the role of the stroma in lung cancer development may benefit from the use of a lung cancer and control group, as well as direct assessment of airway obstruction based on CT imaging rather than the use of $\mathrm{FEV}_{1}$ as a surrogate for impaired lung function (102).

\section{Neoplasia and tumour microenvironment}

Tobacco smoking negatively affects the airway epithelium through both inflammatory and immunosuppressive effects. A recent study explored effects of tobacco smoking on the immune microenvironment in normal human airway epithelium by measuring the levels of $\mathrm{T}$ cell activation and infiltration through gene expression and reported the level of immunosuppression had a stepwise correlation with increased smoking exposure (103). In COPD, epithelial hyperplasia and metaplasia is a result of cigarette smoke and/or infections causing repeated respiratory tract epithelial mucosal damage (104).

Lung cancer has also been demonstrated to develop within metaplastic microenvironments (105). Inflammation can induce hyperplastic lesions under non-neoplastic conditions, however if these lesions undergo uncontrolled proliferation they can transform and adapt a neoplastic and atypical adenomatous appearance, acquiring invasive, angiogenic and metastatic characteristics (10).

It is reported that tumour growth and progression is influenced by bidirectional crosstalk between tumour 
cells and their surrounding stroma, with extracellular cues in the tumour microenvironment also being able to regulate cancer progression and metastasis $(106,107)$. It is therefore important to understand how and when the lung microenvironment is implicated and cells start to promote tumour associated angiogenesis and inflammation (108). Previous studies have been able to identify potential biomarkers for lung cancer diagnosis by analysing and comparing genetic and epigenetic mutations from FFPE histologically normal tissue to matched tumour tissue (109). A study by Keohavong et al. found that KRAS mutations were present in histologically normal tissue surrounding lung tumour in $16 \%$ of patients with lung adenocarcinoma (110). More information is needed to determine when and how these molecular changes occur and what influences these changes, such as inflammation or infection. Understanding the early cellular events that have govern the eventual development of COPD and lung cancer could be guided by studies investigating the gradient from tumour to non-tumour tissue and emphysematous tissue, to help determine at which stage tissue displays neoplastic changes.

\section{Field cancerisation}

Field cancerisation is a theory describing the broad indiscriminate molecular and cellular changes to the surface epithelium that occur in a given anatomical region upon exposure to carcinogens. Early studies by Slaughter and colleagues describes the priming effect of carcinogens and the "field cancerization" of epithelial tissues leading to tumour development (111). The concept suggests that histological abnormalities are shared between neoplasm and adjacent normal appearing tissue, including epithelial hyperplasia and hyperkeratinisation $(111,112)$. These studies hypothesise that somatic alterations can occur naturally or as a result of a mutagenic exposure and drive the formation of a premalignant field which may result in neoplastic growth following clonal expansion. The premalignant fields often occur without any histopathological change and despite having growth and survival advantage, may or may not result in a tumour (113-116). This model of tumorigenesis and further study of cancerized fields may improve predicting cancer development or risk of tumour recurrence (117).

\section{Biological mechanisms shared between COPD and lung cancer}

\section{Inflammation}

COPD patients exhibit pronounced inflammation which positively correlates with disease severity (118), and as this destructive inflammation is operative in emphysema and found in airways and airspaces, this could contribute to lung cancers being developed in proximal and distance tissue (44). Further studies have identified characteristics of immune cells specific to COPD that differ to lung cancer, such that COPD patients have M1 phenotype skewed alveolar macrophages as shown by cells from BAL fluid polarising towards a $\mathrm{T}$ helper $1\left(\mathrm{~T}_{\mathrm{H}} 1\right)$ phenotype through interferon- $\gamma$. Cytokines released include CXCL10, which can induce macrophage elastase from macrophages. The release of IL-8 from alveolar macrophages in conjunction with lung epithelial cells causes the presence of neutrophilic infiltrates in COPD patients. This Th1 cytotoxic profile would seem to be favourable for tumour microenvironment, however does not occur with solid tumours representing a Th2 phenotype activated by M2 macrophages.

Competing disease microenvironments can occur due to the nature of inflammatory cells that surround lung cancers in emphysematous lungs (44). In COPD, the cytotoxic environment has been found to be conducive of tumour initiation due to ROS providing genotoxic stress through macrophages and neutrophils allowing DNA adduct formation to occur leading to genetic mutation. This allows early stage neoplasms in the surrounding microenvironment to release chemokines and cytokines (such as TNF $\alpha$, IL-1 $\beta$, IL- 6 and NF- $\mathrm{NB}$ ) that alter immune cell composition and exhibit direct effects on tumour cells $(44,119,120)$. Additionally, inflammation has been linked to many aspects of lung tumour progression, including cell proliferation, metastasis and response to chemotherapy treatments. For example, IL-17C, which promotes neutrophil recruitment, may promote inflammation in the tumour microenvironment and enhance tumour growth (121).

Independent of the mutagenic effect of tobacco smoke, chronic inflammation observed in COPD is a potential driver of lung cancer development $(67,85,122-124)$. A number of structural and inflammatory cells are involved in the pathogenesis of COPD and lung cancer, particularly neutrophil, macrophages and $\mathrm{CD}^{+}$and $\mathrm{CD} 8^{+}$lymphocytes (125-127). 


\section{Oxidative stress}

Nearly all cases of cancerous tissue show inflammation, and it is possible that the chronic inflammation observed in COPD can be a potent driver for lung cancer development (67). Inflammation is also a major source of reactive nitrogen and oxygen species (RNOS), which in COPD patients levels are persistently elevated (85). Mitochondria is a major cellular source of RNOS and is dysfunctional in COPD. Several studies have linked the methylation of transcription factor A in COPD and squamous cell carcinoma histological subtype of lung cancer (128-130).

\section{DNA damage and repair mechanisms in COPD and lung cancer}

DNA damage caused by reactive oxygen species, single strand breaks and abasic sites is increased in COPD and lung cancer (131-133). Biomass exposure has also been associated with COPD causing an increase in oxidative stress and DNA damage, however levels are more elevated in cigarette smoke induced COPD (134). Studies have shown that the increase in DNA damage is not due to cigarette smoke alone, and COPD patients have increased double strand breaks in their lung compared to smokers and never-smokers without COPD (135). This is potentially due to COPD patients containing higher levels of microsatellite instability and frequency of somatic mutations, as well as a loss of heterozygosity (132). Further increased levels of oxidative DNA damage are found in clusters of functionally significant sequences (VEGF), suggesting that the role oxidative DNA damage plays is not random (136).

\section{Immune mechanisms underlying COPD and lung cancer}

The role of the immune system in lung disease is currently at the forefront of clinical interest. Among COPD patients, immunological changes occur as a result of both T-cell dysregulation (increased $\mathrm{CD}^{+}$, decreased $\mathrm{CD}^{+}$) $(137,138)$ and T-cell exhaustion where effector function is lost as a result of chronic immune checkpoint binding. Further, PD-1 expression in exhausted T-cells has been shown to contribute to altered immune function in COPD patients (139).

In patients with NSCLC, therapeutic inhibition of the immune checkpoint protein PD-1 suppresses T-cell mediated activity, immune evasion and subsequently induces immune-mediated tumour cell death (140). COPD is commonly considered a negative prognostic indicator among lung cancer patients (141), however recent studies have demonstrated an increase in progression-free survival among advanced-stage NSCLC patients with coexisting COPD receiving anti-PD-1 therapy $(142,143)$. Further, the co-expression of PD-1 and T-cell immunoglobulin and mucin domain-containing molecule- 3 (TIM-3) on CD8 ${ }^{+}$ $\mathrm{T}$ cells increases with COPD severity (143). Increased efficacy of anti-PD-1 therapy among these patients may be explained by the immunological dysregulation seen in COPD, leading to increased expression of immune checkpoints among T-cells (144).

Alterations in immune cell composition may be a useful biomarker or therapeutic target in COPD-lung cancer. A recent study demonstrated the increase in Th1-polarized $\mathrm{CD}^{+} \mathrm{T}$-cells in lung tissue is associated with COPD severity and may be a useful biomarker for disease progression (142). Recently, the role of Th17 in COPD and lung cancer progression has been investigated in several clinical and preclinical studies. In a murine model, Chang et al. provided strong evidence for the pathogenic role of Th 17 cells in mediating inflammation and lung tumorigenesis (145). Additional studies confirmed that Th17 is augmented upon exposure to tobacco smoke and is potential therapeutic target in COPD $(142,146)$. There is strong evidence to support the immunological link between COPD and lung cancer and further investigation in this area will have practical and therapeutic impact to aid patient stratification and care.

There is conflicting evidence surrounding the severity of COPD and lung cancer incidence. De Torres and colleagues found that lung cancer incidence decrease with COPD severity, with Global Initiative for Chronic Obstructive Lung Disease (GOLD) stage IV COPD demonstrating less than half of the incidence of lung cancer than stage I (147). This finding may be explained by the notion that the immune system among smokers and mild COPD may be suppressed and less active against tumorigenesis than an active, nontolerant immune system seen in severe COPD cases (147). Conversely, a longitudinal study of 5,402 participants in the first National Health and Nutrition Examination Survey found that lung cancer incidence increased with COPD severity [mild; hazard ratio (HR) $1.4,95 \%$ confidence interval (CI): 0.8-2.6, moderatesevere; HR 2.8, 95\% CI: 1.8-4.4] compared to normal lung function (18). 


\section{The lung microbiome}

The lung microbiome encompasses the community of bacteria, viruses and fungi that resides in the airways and parenchymal tissue. Alterations in the lung microbiome can influence the host's susceptibility to various respiratory diseases through impairment of immune defence mechanisms (148). The lower airways of the lung are inhabited with multiple microbial species and thrives on diversity. Consequently, if bacterial diversity decreases adversely, likely resulting in the dominance of one bacterial species which leads to disrupted mucosal immunity and airway dysbiosis (149).

The microbiome varies with exposure to different environmental factors, and tobacco smoke inhalation has been shown to induce pathological changes to the integrity of the airway epithelial barrier and cell-cell contact via the degradation of tight junction proteins (150), inducing cilia autophagy (151), goblet cell hyperplasia (152) and an increase in epithelial permeability (153).

\section{COPD}

In COPD, the presence of bacteria is associated with mucus hypersecretion, bronchial wall oedema, tertiary lymphoid follicles, and airway and parenchymal inflammation due to defective mucociliary clearance $(14,154)$. Airway structure and integrity is compromised and cellular responses are impacted, which are vital for the control of bacterial growth (155).

COPD patients are predisposed to microbial colonisation and infection of the airways (where pathogenic bacteria, rather than being innocuous, are persistent in the airways causing airway epithelial injury and chronic inflammation (144) and can trigger an exacerbation $(1,156)$.

The identification of predominant bacterial species during stable state and exacerbations in COPD is remains under debate. Erb-Downward et al. found that the Proteobacteria phylum was the predominant bacteria in lung tissue from very severe COPD patients (157). These findings were similar to that of Hilty et al. (158), however, the majority of other studies have concluded that the Firmicutes phylum is the most common in both moderate and severe COPD $(159,160)$. Currently, non-typeable $H$. influenzae, S. pneumoniae, M. catarrbalis and P. aeruginosa are pathogens that are clearly implicated in COPD (156).

Our knowledge of the role of the lung microbiome in COPD is currently inconsistent and results to date are poorly reproducible across studies. The identification of different microbiota varies depending on population, disease severity and methods used to isolate and characterise the microbiome. The presence of different micro-niches across different lung compartments may also explain these divergent results (161). Early studies have reported bacterial diversity decreases as COPD severity increases $(157,158)$, however this has not been confirmed by subsequent studies (162). The use of metagenomics may provide functional data on the microbial interactions and assist in interventional studies in COPD (163).

\section{Lung cancer}

While it is known that the lung microbiome is altered in cases of chronic lung conditions such as COPD compared to healthy controls (164), there is little known about whether there are key microbial species or common lung microbial profiles increasing susceptibility to or enhancing progression of lung cancer. The presence of inflammation in response to Mycobacterium tuberculosis is associated with increased risk of lung cancer (165), and many microbiome studies in colon cancer have demonstrated the carcinogenic influence of bacteria including Bacteroides fragilis and Fusobacterium nucleatum (166). The mechanistic effects of the lung microbiome on tumour development is a rapidly advancing field of study. Recently, Jin and colleagues proposed that commensal lung microbiota promote inflammation and tumour proliferation through the activation of $\gamma \delta \mathrm{T}$-cells and production of IL-17 in the lung (167). Another recent study demonstrated the unique bacterial signature in patients with lung tumours harbouring TP53 mutations (168). This suggest that the microbial composition in lung cancer may be mutation specific, however further elucidation of the molecular and microbial interactions is warranted.

Recent demonstration of the relationship between gut microbiome and responsiveness to immunotherapy have shown that the gut microbiome composition is predictive of anti-PD-1 efficacy in melanoma $(169,170)$ and epithelial tumours including NSCLC (171). These studies demonstrate marked influence of the gut microbiome on therapeutic response, which is expected to have a profound effect on diagnosis and therapeutic strategy as this area of research continues to unfold. 


\section{Biomarkers for diagnosis, interventions and novel therapeutic strategies}

\section{Extracellular vesicles (EVs)}

EVs are nano-sized membranous vesicles that are secreted by both normal and diseased cells to their extracellular environment $(172,173)$. EVs play a key role in local and systemic intercellular communication through the exchange of bioactive molecules such as DNA, mRNA, miRNA, proteins and lipids (174). EVs can be broadly classified into three major vesicle subtypes: apoptotic bodies, microvesicles and exosomes, which are differentiated according to their size, intracellular origin and biogenesis (175). There is a growing body of research implicating EVs in various pathological processes by the selective transfer of nucleic acids, proteins and lipids. The molecular cargo contained in $\mathrm{EVs}$ is reflective of their cellular origin, protected and stable in circulation, and can be non-invasively accessed via blood sampling, which makes them an attractive biomarker for diseases including COPD and lung cancer (175).

The role of EVs in disease includes involvement immune system modulation, angiogenesis, parenchymal remodelling and pre-metastatic niche formation (176). The uptake of EVs into target cells is a specific interaction, which occurs through direct fusion, endocytosis or receptor binding (177). Many studies have postulated that the horizontal transfer and uptake of nucleic acid from EVs may be a key influence the heterogeneity of cancer (178-181)

In relation to COPD, recent studies have identified new molecular mechanisms underlying the disease that are regulated by EVs and their cargo, highlighting a new paradigm for paracrine signalling $(182,183)$. Reports that various stress triggers promote secretion of circulating EVs from lung endothelial cells and that these may be a useful predictive biomarker for assessing the degree of lung endothelial injury in COPD and the disease progression (184).

It has been suggested that $\mathrm{EV}$ miRNAs and proteins may be useful biomarkers for diagnosis of lung cancer (185) as miRNAs have been shown to play an important role in tumorigenesis, metastasis and drug response in lung cancer, with lung cancer derived EV miRNAs having potential as indicators of cancer progression (185) as their contents reflect the molecular dynamics of tumour behaviour both in situ and in metastasis (185).

In addition to the value of $\mathrm{EVs}$ as circulating biomarkers, the potential for exosomes to act as vectors for gene therapy is an emerging topic of interest. Cell-to-cell communication via exchange of translatable RNA offers plausibility for engineering of exosomes to contain DNA or RNA for therapeutic intervention. To date, this genetic exchange has been demonstrated in the tumour microenvironment, by means of a mechanism similar to endocrine signalling in the systemic circulation (174). The absence of host immunogenicity to recipient exosomes processed in vitro, carries a large advantage over viral vectors, many of which initiate immune rejection and require complex methods for delivery enhancement (186).

A recent study by Costales et al. was the first to demonstrate the potential for miRNA to be a druggable target in breast cancer. A small non-protein molecule was designed to recruit an RNAse to selectively cleave miR-96, triggering apoptosis in breast tumour, but not normal cells. The clinical utility of miRNA has further been illuminated by a study reporting that the selective cleavage of miR-96 induces apoptosis in breast tumour cells and is a potential therapeutic target (187). Exploiting the unique biological vehicular nature of exosomes for therapeutic delivery requires further elucidation on the exosomal cargo and their biological functions to aid in the development of exosomes with well-defined composition and activity (188).

\section{Volatile organic compounds (VOCs) for the diagnosis of COPD and lung cancer}

VOCs are a by-product of cellular processes which can be excreted directly from cells into the circulation and diffused into the exhaled breath via the alveolar membrane. Modifications in cellular metabolism, microenvironment and various pathological changes can create a unique VOC profile $(189,190)$. Analysis of VOCs profiles in exhaled breath is performed using one of two commonly used methods: gas chromatography-mass spectrometry (GC-MS) or artificial intelligence devices such as the electronic nose (or e-nose). VOCs analysis is a promising non-invasive method for the diagnosis of lung cancer and COPD and is currently an area of intensive investigation.

Both COPD and lung cancer are characterised by inflammation and oxidative stress within the lung tissue, consequently producing various VOCs which can be excreted in the exhaled breath (189). Several studies have highlighted the clinical potential of exhaled VOCs as a biomarker in pulmonary diseases (191), and recently a study used VOCs patterns to classify 17 diseases (including lung cancer) among 1,404 subjects with $86 \%$ accuracy (192).

Despite being a cost-effective, non-invasive method broad applicability to various diseases, the application of 
these technologies is currently challenged by the intrinsic diversity of pathological conditions and confounding variables such as smoking history, diet, pharmaceuticals and age (193). Furthermore, there is currently no standardised method or means to compare the reliability and replicability of the results obtained between studies. This was demonstrated in a review of ten studies profiling VOCs in lung cancer where only 17/170 VOCs detected in total were cited by more than two studies (194).

\section{Conclusions}

COPD and lung cancer are leading causes of mortality worldwide and share key modifiable and preventable risk factors including tobacco smoking and air pollution exposure. Only a small proportion (10-15\%) of smokers will ultimately develop COPD or lung cancer, indicating that the complex interplay between genetics, epigenetics and environmental factors is key to understanding these diseases. The exact mechanisms behind the increased incidence of lung cancer among COPD patients are yet to be defined, however recent studies provide strong evidence supporting the role of immune dysfunction, the lung microbiome, epigenetic regulation and EVs in the development of COPD and lung cancer.

Early detection and effective, feasible interventions are urgently required to reduce the burden of COPD and lung cancer. Further studies investigating the links between key molecular pathways will continue to elucidate the mechanisms underlying the development of COPD and lung cancer, and provide insights into the development of novel diagnostic and prognostic tools for early intervention and personalised therapeutic strategies.

\section{Acknowledgments}

The Prince Charles Hospital Foundation (BA Parris, HE O'Farrell, KM Fong, IA Yang), The University of Queensland PhD scholarship (BA Parris, HE O'Farrell).

\section{Footnote}

Conflicts of Interest: The authors have no conflicts of interest to declare.

Ethical Statement: The authors are accountable for all aspects of the work in ensuring that questions related to the accuracy or integrity of any part of the work are appropriately investigated and resolved.

\section{References}

1. GOLD. Global Strategy for the Diagnosis, Management, and Prevention of Chronic Obstructive Pulmonary Disease - 2018 Report. 2018. Available online: http://goldcopd. org/wp-content/uploads/2017/11/GOLD-2018-v6.0FINAL-revised-20-Nov_WMS.pdf

2. Soler-Cataluña JJ, Martinez-Garcia MA, Roman Sanchez P, et al. Severe acute exacerbations and mortality in patients with chronic obstructive pulmonary disease. Thorax 2005;60:925-31.

3. Mathers CD, Loncar D. Projections of global mortality and burden of disease from 2002 to 2030. PLoS Med 2006;3:e442.

4. Lung foundation Australia. Economic impact of COPD. 2008. Available online: http://lungfoundation.com.au/ health-professionals/clinical-resources/publications/ economic-impact-of-copd/

5. WHO. COPD predicted to be third leading cause of death in 2030. 2008. Available online: http://www.who.int/ respiratory/copd/World_Health_Statistics_2008/en/

6. Siegel RL, Miller KD, Jemal A. Cancer statistics, 2017. CA Cancer J Clin 2017;67:7-30.

7. Jemal A, Bray F, Center MM, et al. Global cancer statistics. CA Cancer J Clin 2011;61:69-90.

8. Dela Cruz CS, Tanoue LT, Matthay RA. Lung cancer: epidemiology, etiology, and prevention. Clin Chest Med 2011;32:605-44.

9. Hanahan D, Weinberg RA. The hallmarks of cancer. Cell 2000;100:57-70.

10. Hanahan D, Weinberg Robert A. Hallmarks of Cancer: The Next Generation. Cell 2011;144:646-74.

11. Neal JW, Gubens MA, Wakelee HA. Current management of small cell lung cancer. Clin Chest Med 2011;32:853-63.

12. Young RP, Hopkins RJ, Christmas T, et al. COPD prevalence is increased in lung cancer, independent of age, sex and smoking history. Eur Respir J 2009;34:380-6.

13. Adcock IM, Caramori G, Barnes PJ. Chronic obstructive pulmonary disease and lung cancer: new molecular insights. Respiration 2011;81:265-84.

14. Brusselle GG, Joos GF, Bracke KR. New insights into the immunology of chronic obstructive pulmonary disease. Lancet 2011;378:1015-26.

15. Sasaki H, Sekizawa K, Yanai M, et al. Effects of air pollution and smoking on chronic obstructive pulmonary disease and bronchial asthma. Tohoku J Exp Med 
1998;186:151-67.

16. Kumar V, Abbas AK, Aster JC. Robbins basic pathology e-book. 10th edition. Elsevier Health Sciences, 2017.

17. Young RP, Hopkins RJ. How the genetics of lung cancer may overlap with COPD. Respirology 2011;16:1047-55.

18. Mannino DM, Aguayo SM, Petty TL, et al. Low lung function and incident lung cancer in the United States: data From the First National Health and Nutrition Examination Survey follow-up. Arch Intern Med 2003;163:1475-80.

19. Gonzalez J, Marín M, Sánchez-Salcedo P, et al. Lung cancer screening in patients with chronic obstructive pulmonary disease. Ann Transl Med 2016;4:160.

20. Wang $W$, Dou $S$, Dong $W$, et al. Impact of COPD on prognosis of lung cancer: from a perspective on disease heterogeneity. Int J Chron Obstruct Pulmon Dis 2018;13:3767-76.

21. Eisner MD, Anthonisen N, Coultas D, et al. An official American Thoracic Society public policy statement: Novel risk factors and the global burden of chronic obstructive pulmonary disease. Am J Respir Crit Care Med 2010;182:693-718.

22. Paulin LM, Diette GB, Blanc PD, et al. Occupational exposures are associated with worse morbidity in patients with chronic obstructive pulmonary disease. Am J Respir Crit Care Med 2015;191:557-65.

23. Newhouse ML, Berry G. Patterns of mortality in asbestos factory workers in London. Ann N Y Acad Sci 1979;330:53-60.

24. Krewski D, Lubin JH, Zielinski JM, et al. Residential radon and risk of lung cancer: a combined analysis of 7 North American case-control studies. Epidemiology 2005;16:137-45.

25. Darby S, Hill D, Auvinen A, et al. Radon in homes and risk of lung cancer: collaborative analysis of individual data from 13 European case-control studies. BMJ 2005;330:223.

26. Pope CA 3rd, Burnett RT, Thun MJ, et al. Lung cancer, cardiopulmonary mortality, and long-term exposure to fine particulate air pollution. JAMA 2002;287:1132-41.

27. Liu S, Zhou Y, Liu S, et al. Association between exposure to ambient particulate matter and chronic obstructive pulmonary disease: results from a cross-sectional study in China. Thorax 2017;72:788-95.

28. Kurmi OP, Lam KB, Ayres JG. Indoor air pollution and the lung in low- and medium-income countries. Eur Respir J 2012;40:239-54.

29. Zhang JJ, Smith KR. Household Air Pollution from Coal and Biomass Fuels in China: Measurements, Health
Impacts, and Interventions. Environ Health Perspect 2007;115:848-55.

30. Hosgood HD 3rd, Boffetta P, Greenland S, et al. In-home coal and wood use and lung cancer risk: a pooled analysis of the International Lung Cancer Consortium. Environ Health Perspect 2010;118:1743-7.

31. Epplein M, Schwartz SM, Potter JD, et al. Smokingadjusted lung cancer incidence among Asian-Americans (United States). Cancer Causes Control 2005;16:1085-90.

32. Lam WK. Lung cancer in Asian women-the environment and genes. Respirology 2005;10:408-17.

33. Shen XB, Wang GX, Huang YZ, et al. Analysis and estimates of attributable risk factors for lung cancer in Nanjing, China. Lung Cancer 1996;14 Suppl 1:S107-12.

34. Gan WQ, FitzGerald JM, Carlsten C, et al. Associations of ambient air pollution with chronic obstructive pulmonary disease hospitalization and mortality. Am J Respir Crit Care Med 2013;187:721-7.

35. Ezzati M. Indoor air pollution and health in developing countries. Lancet 2005;366:104-6.

36. Zhou Y, Zou Y, Li X, et al. Lung function and incidence of chronic obstructive pulmonary disease after improved cooking fuels and kitchen ventilation: a 9-year prospective cohort study. PLoS Med 2014;11:e1001621.

37. Metayer C, Wang Z, Kleinerman RA, et al. Cooking oil fumes and risk of lung cancer in women in rural Gansu, China. Lung Cancer 2002;35:111-7.

38. Ko YC, Cheng LS, Lee CH, et al. Chinese food cooking and lung cancer in women nonsmokers. Am J Epidemiol 2000;151:140-7.

39. Lin PC, Peng CY, Pan CH, et al. Gender differences and lung cancer risk in occupational chefs: analyzing more than 350,000 chefs in Taiwan, 1984-2011. Int Arch Occup Environ Health 2019;92:101-9.

40. Young SC, Chang LW, Lee HL, et al. DNA damages induced by trans, trans-2,4-decadienal (tt-DDE), a component of cooking oil fume, in human bronchial epithelial cells. Environ Mol Mutagen 2010;51:315-21.

41. Purcaro G, Navas JA, Guardiola F, et al. Polycyclic aromatic hydrocarbons in frying oils and snacks. J Food Prot 2006;69:199-204.

42. Tuder RM, Petrache I. Pathogenesis of chronic obstructive pulmonary disease. J Clin Invest 2012;122:2749-55.

43. Stratton MR. Exploring the Genomes of Cancer Cells: Progress and Promise. Science 2011;331:1553-8.

44. Houghton AM. Mechanistic links between COPD and lung cancer. Nat Rev Cancer 2013;13:233-45.

45. Turner MC, Chen Y, Krewski D, et al. Chronic obstructive 
pulmonary disease is associated with lung cancer mortality in a prospective study of never smokers. Am J Respir Crit Care Med 2007;176:285-90.

46. Silverman EK, Sandhaus RA. Clinical practice. Alpha1antitrypsin deficiency. N Engl J Med 2009;360:2749-57.

47. Cho MH, McDonald ML, Zhou X, et al. Risk loci for chronic obstructive pulmonary disease: a genome-wide association study and meta-analysis. Lancet Respir Med 2014;2:214-25.

48. Cancer Genome Atlas Research Network. Comprehensive molecular profiling of lung adenocarcinoma. Nature 2014;511:543-50. Erratum in: Nature 2014;514:262.

49. Imielinski $M$, Berger Alice H, Hammerman Peter S, et al. Mapping the Hallmarks of Lung Adenocarcinoma with Massively Parallel Sequencing. Cell 2012;150:1107-20.

50. Lawrence MS, Stojanov P, Polak P, et al. Mutational heterogeneity in cancer and the search for new cancerassociated genes. Nature 2013;499:214.

51. Nitadori J, Inoue M, Iwasaki M, et al. Association between lung cancer incidence and family history of lung cancer: data from a large-scale population-based cohort study, the JPHC study. Chest 2006;130:968-75.

52. Bailey-Wilson JE, Amos CI, Pinney SM, et al. A major lung cancer susceptibility locus maps to chromosome 6q23-25. Am J Hum Genet 2004;75:460-74.

53. Matakidou A, Eisen T, Houlston RS. Systematic review of the relationship between family history and lung cancer risk. Br J Cancer 2005;93:825-33.

54. Li X, Hemminki K. Familial multiple primary lung cancers: a population-based analysis from Sweden. Lung Cancer 2005;47:301-7.

55. Amos CI, Pinney SM, Li Y, et al. A susceptibility locus on chromosome 6q greatly increases lung cancer risk among light and never smokers. Cancer Res 2010;70:2359-67.

56. Couraud S, Zalcman G, Milleron B, et al. Lung cancer in never smokers--a review. Eur J Cancer 2012;48:1299-311.

57. Sun S, Schiller JH, Gazdar AF. Lung cancer in never smokers--a different disease. Nat Rev Cancer 2007;7:778-90.

58. Hung RJ, Boffetta P, Brockmoller J, et al. CYP1A1 and GSTM1 genetic polymorphisms and lung cancer risk in Caucasian non-smokers: a pooled analysis. Carcinogenesis 2003;24:875-82.

59. Lo Iacono M, Monica V, Saviozzi S, et al. p63 and p73 isoform expression in non-small cell lung cancer and corresponding morphological normal lung tissue. J Thorac Oncol 2011;6:473-81.

60. Oh SS, Chang SC, Cai L, et al. Single nucleotide polymorphisms of 8 inflammation-related genes and their associations with smoking-related cancers. Int J Cancer 2010;127:2169-82.

61. Lim WY, Chen Y, Ali SM, et al. Polymorphisms in inflammatory pathway genes, host factors and lung cancer risk in Chinese female never-smokers. Carcinogenesis 2011;32:522-9.

62. Bechtel JJ, Kelley WA, Coons TA, et al. Lung cancer detection in patients with airflow obstruction identified in a primary care outpatient practice. Chest 2005;127:1140-5.

63. Amos CI, Wu X, Broderick P, et al. Genome-wide association scan of tag SNPs identifies a susceptibility locus for lung cancer at $15 \mathrm{q} 25.1$. Nat Genet 2008;40:616-22.

64. Hancock DB, Eijgelsheim M, Wilk JB, et al. Meta-analyses of genome-wide association studies identify multiple loci associated with pulmonary function. Nat Genet 2010;42:45-52.

65. Pillai SG, Ge D, Zhu G, et al. A Genome-Wide Association Study in Chronic Obstructive Pulmonary Disease (COPD): Identification of Two Major Susceptibility Loci. PLOS Genetics 2009;5:e1000421.

66. Wang X, Li W, Huang K, et al. Genetic variants in ADAM33 are associated with airway inflammation and lung function in COPD. BMC Pulm Med 2014;14:173.

67. Schetter AJ, Heegaard NH, Harris CC. Inflammation and cancer: interweaving microRNA, free radical, cytokine and p53 pathways. Carcinogenesis 2010;31:37-49.

68. Van Dyke AL, Cote ML, Wenzlaff AS, et al. Chromosome 5p Region SNPs Are Associated with Risk of NSCLC among Women. J Cancer Epidemiol 2009;2009:242151.

69. Young RP, Hopkins RJ, Gamble GD, et al. Genetic evidence linking lung cancer and COPD: a new perspective. Appl Clin Genet 2011;4:99-111.

70. Young RP, Whittington CF, Hopkins RJ, et al. Chromosome 4q31 locus in COPD is also associated with lung cancer. Eur Respir J 2010;36:1375-82.

71. Wilk JB, Chen TH, Gottlieb DJ, et al. A genome-wide association study of pulmonary function measures in the Framingham Heart Study. PLoS Genet 2009;5:e1000429.

72. Sakornsakolpat P, Prokopenko D, Lamontagne M, et al. Genetic landscape of chronic obstructive pulmonary disease identifies heterogeneous cell-type and phenotype associations. Nat Genet 2019;51:494-505.

73. Young RP, Hopkins RJ. Link between COPD and lung cancer. Respir Med 2010;104:758-9.

74. Ding L, Getz G, Wheeler DA, et al. Somatic mutations affect key pathways in lung adenocarcinoma. Nature 
2008;455:1069-75.

75. Rosell R, Moran T, Queralt C, et al. Screening for epidermal growth factor receptor mutations in lung cancer. N Engl J Med 2009;361:958-67.

76. Salomon DS, Brandt R, Ciardiello F, et al. Epidermal growth factor-related peptides and their receptors in human malignancies. Crit Rev Oncol Hematol 1995;19:183-232.

77. Garcia de Palazzo IE, Adams GP, Sundareshan P, et al. Expression of mutated epidermal growth factor receptor by non-small cell lung carcinomas. Cancer Res 1993;53:3217-20.

78. Parris BA, Shaw E, Pang B, et al. Somatic mutations and immune checkpoint biomarkers. Respirology 2019;24:215-26.

79. Cohen MH, Williams GA, Sridhara R, et al. FDA drug approval summary: gefitinib (ZD1839) (Iressa) tablets. Oncologist 2003;8:303-6.

80. Zhang X, Chang A. Somatic mutations of the epidermal growth factor receptor and non-small-cell lung cancer. J Med Genet 2007;44:166-72.

81. Amann J, Kalyankrishna S, Massion PP, et al. Aberrant epidermal growth factor receptor signaling and enhanced sensitivity to EGFR inhibitors in lung cancer. Cancer Res 2005;65:226-35.

82. Anderson GP, Bozinovski S. Acquired somatic mutations in the molecular pathogenesis of COPD. Trends Pharmacol Sci 2003;24:71-6.

83. Di Stefano A, Caramori G, Oates T, et al. Increased expression of nuclear factor-kappaB in bronchial biopsies from smokers and patients with COPD. Eur Respir J 2002;20:556-63.

84. Wistuba II. Histologic Evaluation of Bronchial Squamous Lesions: Any Role in Lung Cancer Risk Assessment? Clin Cancer Res 2005;11:1358-60.

85. Durham AL, Adcock IM. The relationship between COPD and lung cancer. Lung Cancer 2015;90:121-7.

86. Guilleret I, Yan P, Grange F, et al. Hypermethylation of the human telomerase catalytic subunit (hTERT) gene correlates with telomerase activity. Int J Cancer 2002;101:335-41.

87. Liloglou T, Bediaga NG, Brown BR, et al. Epigenetic biomarkers in lung cancer. Cancer Lett 2014;342:200-12.

88. Qiu W, Baccarelli A, Carey VJ, et al. Variable DNA Methylation Is Associated with Chronic Obstructive Pulmonary Disease and Lung Function. Am J Respir Crit Care Med 2012;185:373-81.

89. Sato T, Teramukai S, Kondo H, et al. Impact and predictors of acute exacerbation of interstitial lung diseases after pulmonary resection for lung cancer. J Thorac Cardiovasc Surg 2014;147:1604-1611.e3.

90. Tessema M, Yingling CM, Picchi MA, et al. Epigenetic Repression of CCDC37 and MAP1B Links Chronic Obstructive Pulmonary Disease to Lung Cancer. J Thorac Oncol 2015;10:1181-8.

91. Ling H, Fabbri M, Calin GA. MicroRNAs and other noncoding RNAs as targets for anticancer drug development. Nat Rev Drug Discov 2013;12:847-65.

92. Shivdasani RA. MicroRNAs: regulators of gene expression and cell differentiation. Blood 2006;108:3646-53.

93. Rebane A, Akdis CA. MicroRNAs: Essential players in the regulation of inflammation. J Allergy Clin Immunol 2013;132:15-26.

94. Conickx G, Mestdagh P, Avila Cobos F, et al. MicroRNA Profiling Reveals a Role for MicroRNA-218-5p in the Pathogenesis of Chronic Obstructive Pulmonary Disease. Am J Respir Crit Care Med 2017;195:43-56.

95. Kim WJ, Lim JH, Hong Y, et al. Altered miRNA expression in lung tissues of patients with chronic obstructive pulmonary disease. Mol Cell Toxicol 2017;13:207-12.

96. Keller A, Fehlmann T, Ludwig N, et al. Genome-wide MicroRNA Expression Profiles in COPD: Early Predictors for Cancer Development. Genomics Proteomics Bioinformatics 2018;16:162-71.

97. Mateu-Jimenez M, Curull V, Rodriguez-Fuster A, et al. Profile of epigenetic mechanisms in lung tumors of patients with underlying chronic respiratory conditions. Clin Epigenetics 2018;10:7.

98. Kim WJ, Lim JH, Lee JS, et al. Comprehensive Analysis of Transcriptome Sequencing Data in the Lung Tissues of COPD Subjects. Int J Genomics 2015;2015:206937.

99. Ahn SY, Park WS, Kim YE, et al. Vascular endothelial growth factor mediates the therapeutic efficacy of mesenchymal stem cell-derived extracellular vesicles against neonatal hyperoxic lung injury. Exp Mol Med 2018;50:26.

100. Valkenburg KC, de Groot AE, Pienta KJ. Targeting the tumour stroma to improve cancer therapy. Nat Rev Clin Oncol 2018;15:366-81.

101. Sandri BJ, Masvidal L, Murie C, et al. Distinct CancerPromoting Stromal Gene Expression Depending on Lung Function. Am J Respir Crit Care Med 2019;200:348-58.

102. Christenson S, Hersh CP. Found in Translation: Multiomics Assessment of the Chronic Obstructive Pulmonary Disease-Lung Cancer Interaction. Am J Respir Crit Care Med 2019;200:276-7. 
103. Wang J, Linxweiler M, Yang W, et al. Immunomodulatory and immunotherapeutic implications of tobacco smoking in squamous cell carcinomas and normal airway epithelium. Oncotarget 2019;10:3835-9.

104. Puchelle E, Zahm JM, Tournier JM, et al. Airway epithelial repair, regeneration, and remodeling after injury in chronic obstructive pulmonary disease. Proc Am Thorac Soc 2006;3:726-33.

105. Vine MF, Schoenbach VJ, Hulka BS, et al. Atypical metaplasia and incidence of bronchogenic carcinoma. Am J Epidemiol 1990;131:781-93.

106. Quail DF, Joyce JA. Microenvironmental regulation of tumor progression and metastasis. Nat Med 2013;19:1423-37.

107.Abdullah M, Kahler D, Vock C, et al. Pulmonary haptoglobin and CD163 are functional immunoregulatory elements in the human lung. Respiration 2012;83:61-73.

108. Lim SB, Tan SJ, Lim W-T, et al. An extracellular matrixrelated prognostic and predictive indicator for early-stage non-small cell lung cancer. Nat Commun 2017;8:1734.

109. Daugaard I, Dominguez D, Kjeldsen TE, et al. Identification and validation of candidate epigenetic biomarkers in lung adenocarcinoma. Sci Rep 2016;6:35807.

110. Keohavong P, Mady HH, Gao WM, et al. Topographic analysis of K-ras mutations in histologically normal lung tissues and tumours of lung cancer patients. Br J Cancer 2001;85:235-41.

111. Slaughter DP, Southwick HW, Smejkal W. Field cancerization in oral stratified squamous epithelium; clinical implications of multicentric origin. Cancer 1953;6:963-8.

112.Steiling K, Ryan J, Brody JS, et al. The field of tissue injury in the lung and airway. Cancer Prev Res (Phila) 2008; 1:396-403.

113. Nelson HH, Christiani DC, Mark EJ, et al. Implications and prognostic value of K-ras mutation for early-stage lung cancer in women. J Natl Cancer Inst 1999;91:2032-8.

114. Franklin WA, Gazdar AF, Haney J, et al. Widely dispersed p53 mutation in respiratory epithelium. A novel mechanism for field carcinogenesis. J Clin Invest 1997;100:2133-7.

115. Gomperts BN, Walser TC, Spira A, et al. Enriching the molecular definition of the airway "field of cancerization:" establishing new paradigms for the patient at risk for lung cancer. Cancer Prev Res (Phila) 2013;6:4-7.

116. Kadara H, Fujimoto J, Yoo SY, et al. Transcriptomic architecture of the adjacent airway field cancerization in non-small cell lung cancer. J Natl Cancer Inst 2014;106:dju004.

117. Curtius K, Wright NA, Graham TA. An evolutionary perspective on field cancerization. Nat Rev Cancer 2018;18:19-32.

118.Hogg JC, Chu F, Utokaparch S, et al. The nature of smallairway obstruction in chronic obstructive pulmonary disease. N Engl J Med 2004;350:2645-53.

119. Haqqani AS, Sandhu JK, Birnboim HC. Expression of interleukin-8 promotes neutrophil infiltration and genetic instability in mutatect tumors. Neoplasia 2000;2:561-8.

120. Dinarello CA. The paradox of pro-inflammatory cytokines in cancer. Cancer Metastasis Rev 2006;25:307-13.

121.Jungnickel C, Schmidt LH, Bittigkoffer L, et al. IL-17C mediates the recruitment of tumor-associated neutrophils and lung tumor growth. Oncogene 2017;36:4182-90.

122. de-Torres JP, Wilson DO, Sanchez-Salcedo P, et al. Lung cancer in patients with chronic obstructive pulmonary disease. Development and validation of the COPD Lung Cancer Screening Score. Am J Respir Crit Care Med 2015;191:285-91.

123. Shacter E, Weitzman SA. Chronic inflammation and cancer. Oncology (Williston Park) 2002;16:217-26, 229; discussion 230-2.

124. Yang IA, Relan V, Wright CM, et al. Common pathogenic mechanisms and pathways in the development of COPD and lung cancer. Expert Opin Ther Targets 2011;15:439-56.

125. Gomes M, Teixeira AL, Coelho A, et al. The role of inflammation in lung cancer. Adv Exp Med Biol 2014;816:1-23.

126. Barnes PJ, Shapiro SD, Pauwels RA. Chronic obstructive pulmonary disease: molecular and cellular mechanisms. Eur Respir J 2003;22:672-88.

127. Paone G, Conti V, Vestri A, et al. Analysis of sputum markers in the evaluation of lung inflammation and functional impairment in symptomatic smokers and COPD patients. Dis Markers 2011;31:91-100.

128. Lennon FE, Salgia R. Mitochondrial dynamics: biology and therapy in lung cancer. Expert Opin Investig Drugs 2014;23:675-92.

129. Hoffmann RF, Zarrintan S, Brandenburg SM, et al. Prolonged cigarette smoke exposure alters mitochondrial structure and function in airway epithelial cells. Respir Res 2013;14:97.

130.Peng C, Tian C, Zhang Y, et al. C-reactive protein levels predict bacterial exacerbation in patients with chronic obstructive pulmonary disease. Am J Med Sci 2013;345:190-4. 
131. Deslee G, Adair-Kirk TL, Betsuyaku T, et al. Cigarette Smoke Induces Nucleic-Acid Oxidation in Lung Fibroblasts. Am J Respir Cell Mol Biol 2010;43:576-84.

132. Tzortzaki EG, Dimakou K, Neofytou E, et al. Oxidative DNA damage and somatic mutations: a link to the molecular pathogenesis of chronic inflammatory airway diseases. Chest 2012;141:1243-50.

133. Caramori G, Casolari P, Cavallesco GN, et al. Mechanisms involved in lung cancer development in COPD. Int J Biochem Cell Biol 2011;43:1030-44.

134. Ceylan E, Kocyigit A, Gencer M, et al. Increased DNA damage in patients with chronic obstructive pulmonary disease who had once smoked or been exposed to biomass. Respir Med 2006;100:1270-6.

135.Aoshiba K, Zhou F, Tsuji T, et al. DNA damage as a molecular link in the pathogenesis of COPD in smokers. Eur Respir J 2012;39:1368-76.

136. Sears CR. DNA repair as an emerging target for COPDlung cancer overlap. Respir Investig 2019;57:111-21.

137.McKendry RT, Spalluto CM, Burke H, et al. Dysregulation of Antiviral Function of CD8(+) T Cells in the Chronic Obstructive Pulmonary Disease Lung. Role of the PD-1PD-L1 Axis. Am J Respir Crit Care Med 2016;193:642-51. 138. O'Shaughnessy TC, Ansari TW, Barnes NC, et al. Inflammation in bronchial biopsies of subjects with chronic bronchitis: inverse relationship of CD8+ T lymphocytes with FEV1. Am J Respir Crit Care Med 1997;155:852-7.

139. Kalathil SG, Lugade AA, Pradhan V, et al. T-regulatory cells and programmed death $1+T$ cells contribute to effector T-cell dysfunction in patients with chronic obstructive pulmonary disease. Am J Respir Crit Care Med 2014;190:40-50.

140.Domingues D, Turner A, Silva MD, et al. Immunotherapy and lung cancer: current developments and novel targeted therapies. Immunotherapy 2014;6:1221-35.

141.Jian ZH, Huang JY, Nfor ON, et al. Pre-existing Pulmonary Diseases and Survival in Patients With Stagedependent Lung Adenocarcinoma: A STROBE-compliant Article. Medicine (Baltimore) 2016;95:e2987.

142. Mark NM, Kargl J, Busch SE, et al. Chronic Obstructive Pulmonary Disease Alters Immune Cell Composition and Immune Checkpoint Inhibitor Efficacy in NonSmall Cell Lung Cancer. Am J Respir Crit Care Med 2018;197:325-36.

143. Biton J, Ouakrim H, Dechartres A, et al. Impaired Tumor-Infiltrating T Cells in Patients with Chronic Obstructive Pulmonary Disease Impact Lung Cancer Response to PD-1 Blockade. Am J Respir Crit Care Med
2018;198:928-40.

144. Chalela R, Gea J, Barreiro E. Immune phenotypes in lung cancer patients with COPD: potential implications for immunotherapy. J Thorac Dis 2018;10:S2186-9.

145. Chang SH, Mirabolfathinejad SG, Katta H, et al. T helper 17 cells play a critical pathogenic role in lung cancer. Proc Natl Acad Sci U S A 2014;111:5664-9.

146. Chen K, Pociask DA, McAleer JP, et al. IL-17RA is required for CCL2 expression, macrophage recruitment, and emphysema in response to cigarette smoke. PLoS One 2011;6:e20333.

147. de Torres JP, Marin JM, Casanova C, et al. Lung cancer in patients with chronic obstructive pulmonary disease-incidence and predicting factors. Am J Respir Crit Care Med 2011;184:913-9.

148. King PT, MacDonald M, Bardin PG. Bacteria in COPD; their potential role and treatment. Transl Respir Med 2013;1:13.

149. Shaw JG, Vaughan A, Dent AG, et al. Biomarkers of progression of chronic obstructive pulmonary disease (COPD). J Thorac Dis 2014;6:1532-47.

150. Heijink IH, Brandenburg SM, Postma DS, et al. Cigarette smoke impairs airway epithelial barrier function and cellcell contact recovery. Eur Respir J 2012;39:419-28.

151. Cloonan SM, Lam HC, Ryter SW, et al. "Ciliophagy": The consumption of cilia components by autophagy. Autophagy 2014;10:532-4.

152. Schamberger AC, Mise N, Jia J, et al. Cigarette smokeinduced disruption of bronchial epithelial tight junctions is prevented by transforming growth factor-beta. Am J Respir Cell Mol Biol 2014;50:1040-52.

153. Mishra R, Foster D, Vasu VT, et al. Cigarette Smoke Induces Human Epidermal Receptor 2-Dependent Changes in Epithelial Permeability. Am J Respir Cell Mol Biol 2016;54:853-64.

154. Beck JM, Young VB, Huffnagle GB. The microbiome of the lung. Transl Res 2012;160:258-66.

155.Herr C, Shaykhiev R, Bals R. The role of cathelicidin and defensins in pulmonary inflammatory diseases. Expert Opin Biol Ther 2007;7:1449-61.

156. Rangelov K, Sethi S. Role of infections. Clin Chest Med 2014;35:87-100.

157.Erb-Downward JR, Thompson DL, Han MK, et al. Analysis of the lung microbiome in the "healthy" smoker and in COPD. PLoS One 2011;6:e16384.

158. Hilty M, Burke C, Pedro H, et al. Disordered microbial communities in asthmatic airways. PLoS One 2010;5:e8578. 
159.Pragman AA, Kim HB, Reilly CS, et al. The lung microbiome in moderate and severe chronic obstructive pulmonary disease. PLoS One 2012; 7:e47305.

160. Huang YJ, Sethi S, Murphy T, et al. Airway microbiome dynamics in exacerbations of chronic obstructive pulmonary disease. J Clin Microbiol 2014;52:2813-23.

161. Sze MA, Hogg JC, Sin DD. Bacterial microbiome of lungs in COPD. Int J Chron Obstruct Pulmon Dis 2014;9:229-38.

162. Sze MA, Dimitriu PA, Hayashi S, et al. The lung tissue microbiome in chronic obstructive pulmonary disease. Am J Respir Crit Care Med 2012;185:1073-80.

163. Monsó E. Microbiome in chronic obstructive pulmonary disease. Ann Transl Med 2017;5:251.

164. Kim HJ, Kim YS, Kim KH, et al. The microbiome of the lung and its extracellular vesicles in nonsmokers, healthy smokers and COPD patients. Exp Mol Med 2017;49:e316.

165. Shiels MS, Albanes D, Virtamo J, et al. Increased risk of lung cancer in men with tuberculosis in the alphatocopherol, beta-carotene cancer prevention study. Cancer Epidemiol Biomarkers Prev 2011;20:672-8.

166. Kostic AD, Chun E, Robertson L, et al. Fusobacterium nucleatum potentiates intestinal tumorigenesis and modulates the tumor-immune microenvironment. Cell Host Microbe 2013;14:207-15.

167.Jin C, Lagoudas GK, Zhao C, et al. Commensal Microbiota Promote Lung Cancer Development via gammadelta T Cells. Cell 2019;176:998-1013.e16.

168. Greathouse KL, White JR, Vargas AJ, et al. Interaction between the microbiome and TP53 in human lung cancer. Genome Biol 2018;19:123.

169. Sivan A, Corrales L, Hubert N, et al. Commensal Bifidobacterium promotes antitumor immunity and facilitates anti-PD-L1 efficacy. Science 2015;350:1084-9.

170. Matson V, Fessler J, Bao R, et al. The commensal microbiome is associated with anti-PD-1 efficacy in metastatic melanoma patients. Science 2018;359:104-8.

171. Routy B, Le Chatelier E, Derosa L, et al. Gut microbiome influences efficacy of PD-1-based immunotherapy against epithelial tumors. Science 2018;359:91-7.

172.Zaborowski MP, Balaj L, Breakefield XO, et al. Extracellular Vesicles: Composition, Biological Relevance, and Methods of Study. BioScience 2015;65:783-97.

173. Colombo M, Raposo G, Thery C. Biogenesis, secretion, and intercellular interactions of exosomes and other extracellular vesicles. Annu Rev Cell Dev Biol 2014;30:255-89.

174. Valadi H, Ekstrom K, Bossios A, et al. Exosome-mediated transfer of mRNAs and microRNAs is a novel mechanism of genetic exchange between cells. Nat Cell Biol 2007;9:654-9.

175. Théry C, Witwer KW, Aikawa E, et al. Minimal information for studies of extracellular vesicles 2018 (MISEV2018): a position statement of the International Society for Extracellular Vesicles and update of the MISEV2014 guidelines. J Extracell Vesicles 2018;7:1535750.

176. Becker A, Thakur BK, Weiss JM, et al. Extracellular Vesicles in Cancer: Cell-to-Cell Mediators of Metastasis. Cancer Cell 2016;30:836-48.

177. Cocucci E, Racchetti G, Meldolesi J. Shedding microvesicles: artefacts no more. Trends Cell Biol 2009;19:43-51.

178.Al-Nedawi K, Meehan B, Micallef J, et al. Intercellular transfer of the oncogenic receptor EGFRvIII by microvesicles derived from tumour cells. Nat Cell Biol 2008;10:619-24.

179. Di Vizio D, Kim J, Hager MH, et al. Oncosome formation in prostate cancer: association with a region of frequent chromosomal deletion in metastatic disease. Cancer Res 2009;69:5601-9.

180.Zomer A, van Rheenen J. Implications of Extracellular Vesicle Transfer on Cellular Heterogeneity in Cancer: What Are the Potential Clinical Ramifications? Cancer Res 2016;76:2071-5.

181. Hoshino A, Costa-Silva B, Shen TL, et al. Tumour exosome integrins determine organotropic metastasis. Nature 2015;527:329-35.

182. Fujita Y, Kosaka N, Araya J, et al. Extracellular vesicles in lung microenvironment and pathogenesis. Trends Mol Med 2015;21:533-42.

183. Serban KA, Rezania S, Petrusca DN, et al. Structural and functional characterization of endothelial microparticles released by cigarette smoke. Sci Rep 2016;6:31596.

184. Takahashi T, Kubo H. The role of microparticles in chronic obstructive pulmonary disease. Int J Chron Obstruct Pulmon Dis 2014;9:303-14.

185. Fujita Y, Kuwano K, Ochiya T, et al. The impact of extracellular vesicle-encapsulated circulating microRNAs in lung cancer research. Biomed Res Int 2014;2014:486413.

186. Murakami Y, Toyoda H, Tanahashi T, et al. Comprehensive miRNA Expression Analysis in Peripheral Blood Can Diagnose Liver Disease. PLoS One 2012;7:e48366.

187. Costales MG, Matsumoto Y, Velagapudi SP, et al. Small Molecule Targeted Recruitment of a Nuclease to RNA. J 
Am Chem Soc 2018;140:6741-4.

188. Ferguson SW, Nguyen J. Exosomes as therapeutics: The implications of molecular composition and exosomal heterogeneity. J Control Release 2016;228:179-90.

189. Nardi-Agmon I, Peled N. Exhaled breath analysis for the early detection of lung cancer: recent developments and future prospects. Lung Cancer (Auckl) 2017;8:31-8.

190.van de Kant KD, van der Sande LJ, Jöbsis Q, et al. Clinical use of exhaled volatile organic compounds in pulmonary diseases: a systematic review. Respir Res 2012;13:117.

191. Gasparri R, Sedda G, Spaggiari L. Volatile organic compounds and lung cancer: a tight link useful for diagnosis. Shanghai Chest 2018;2:95.

Cite this article as: Parris BA, O'Farrell HE, Fong KM, Yang IA. Chronic obstructive pulmonary disease (COPD) and lung cancer: common pathways for pathogenesis. J Thorac Dis 2019;11(Suppl 17):S2155-S2172. doi: 10.21037/jtd.2019.10.54
192. Nakhleh MK, Amal H, Jeries R, et al. Diagnosis and Classification of 17 Diseases from 1404 Subjects via Pattern Analysis of Exhaled Molecules. ACS Nano 2017;11:112-25.

193. Kischkel S, Miekisch W, Sawacki A, et al. Breath biomarkers for lung cancer detection and assessment of smoking related effects--confounding variables, influence of normalization and statistical algorithms. Clin Chim Acta 2010;411:1637-44.

194. D'Amico A, Pennazza G, Santonico M, et al. An investigation on electronic nose diagnosis of lung cancer. Lung Cancer 2010;68:170-6. 